\title{
Delays in obstetric care increase the risk of neonatal near-miss morbidity events and death: a case-control study
}

Ocilia Maria Costa Carvalho ${ }^{1 *}$ (D), Antônio Brazil Viana Junior ${ }^{2}$, Matheus Costa Carvalho Augusto ${ }^{3}$, Álvaro Jorge Madeiro Leite ${ }^{1,4}$, Rivianny Arrais Nobre ${ }^{3,4}$, Olivia Andrea Alencar Costa Bessa ${ }^{3}$, Eveline Campos Monteiro de Castro ${ }^{5}$, Fernanda Nogueira Barbosa Lopes ${ }^{1}$ and Francisco Herlânio Costa Carvalho ${ }^{1,4,5}$

\begin{abstract}
Background: To evaluate the association between delays in obstetric care and neonatal near-miss mortality events and death in a public maternity referral center.

Methods: This case-control study enrolled 142 neonates, meeting the near-miss criteria of 5-min Apgar $<7$, weight $<1500 \mathrm{~g}$, gestational age $<32$ weeks, and use of mechanical ventilation or congenital malformation, as well as 284 controls (without the near-miss criteria), at a ratio of 1:2. After follow-up, the following outcomes were reclassified: survival of the neonatal period without the near-miss criteria (true "controls"), "near-miss," and "neonatal death." Maternal sociodemographic characteristics, prenatal care, and pregnancy resolution were evaluated. Pearson's chi-square and Fisher's exact tests were used. Simple logistic regression was performed to determine the association between the three delay factors with near-miss outcomes and/or neonatal death. The variables that had maintained values of $p<0.05$ were subjected to multinomial logistic regression.
\end{abstract}

Results: Comparisons revealed the following associations: for controls and near-miss events, delayed access to health services due to a lack of specialized services (odds ratio [OR], 3.0; 95\% confidence interval [CI], 1.8-5.1) and inappropriate conduct with the patient $(\mathrm{OR}, 12.1 ; 95 \% \mathrm{Cl}, 1.3-108.7)$; for controls and death, absent or inadequate prenatal care $(\mathrm{OR}, 3.3 ; 95 \% \mathrm{Cl}, 1.6-7.1)$ and delayed access to health services due to a lack of specialized services $(\mathrm{OR}, 2.5 ; 95 \% \mathrm{Cl}, 1.1-5.6)$; and for near-miss events and death, absent or inadequate prenatal care $(\mathrm{OR}, 2.2 ; 95 \% \mathrm{Cl}$, 1.0-5.0). Logistic regression for the combined outcome (near-miss plus neonatal deaths) revealed absent or inadequate prenatal care $(\mathrm{OR}, 1.9 ; 95 \% \mathrm{Cl}, 1.2-2.8)$, lack of specialized services $(\mathrm{OR}, 2.8 ; 95 \% \mathrm{Cl}, 1.7-4.5)$, and improper conduct with the patient (OR, 10.6; $95 \% \mathrm{Cl}, 1.2-91.8)$.

Conclusions: The delays in obstetric care associated with the presence of near-miss and/or neonatal death included absent or inadequate prenatal care, delayed access to health services due to a lack of specialized services, and inappropriate conduct with the patient.

Keywords: Near-miss, Healthcare, Comprehensive healthcare, Infant, Mortality

\footnotetext{
* Correspondence: ociliacarvalho@hotmail.com

'Departamento de Saúde Comunitária / Universidade Federal do Ceará. Fortaleza, Fortaleza, CE, Brazil

Full list of author information is available at the end of the article
}

(c) The Author(s). 2020 Open Access This article is licensed under a Creative Commons Attribution 4.0 International License, which permits use, sharing, adaptation, distribution and reproduction in any medium or format, as long as you give appropriate credit to the original author(s) and the source, provide a link to the Creative Commons licence, and indicate if changes were made. The images or other third party material in this article are included in the article's Creative Commons. licence, unless indicated otherwise in a credit line to the material. If material is not included in the article's Creative Commons licence and your intended use is not permitted by statutory regulation or exceeds the permitted use, you will need to obtain permission directly from the copyright holder. To view a copy of this licence, visit http://creativecommons.org/licenses/by/4.0/ The Creative Commons Public Domain Dedication waiver (http://creativecommons.org/publicdomain/zero/1.0/) applies to the data made available in this article, unless otherwise stated in a credit line to the data. 


\section{Background}

Neonatal morbimortality is used as a parameter to evaluate the quality of healthcare during the prenatal and childbirth periods. It also helps evaluate population healthcare and socioeconomic development levels [1, 2].

Neonatal near-miss morbidity is defined as the near death of a newborn due to a serious complication during the first 28 days of life. Studies have shown that the number of survivors affected by such morbidities is two to six times higher than the number of neonates who died [3].

The main components of infant mortality are concentrated in the neonatal period. In 2016, approximately 5.6 million children died worldwide, almost half (46\%) within the first 28 days of life [4].

The main causes of mortality in the neonatal period are infectious diseases and neonatal complications. In Brazil, $39 \%$ of these deaths are associated with the care provided to pregnant women and $14 \%$ are directly associated with delivery $[5,6]$. In this context, avoidable causes are protagonists and relevant obstetric complications. Factors involving neonatal morbimortality are inseparable from maternal health problems, being influenced by prenatal, delivery, and postnatal continuous care in the health system $[3,6]$.

Neonatal mortality rates have decreased worldwide. Brazil has followed this trend by providing important measures, such as a mother and baby healthcare program with direct actions related to pregnancy, delivery, and birth [7, 8]. Despite this advance, statistics are still alarming and demand urgent action.

In the 1990s, Thaddeus and Maine created an evaluation model to study maternal deaths since they were concerned about how pregnant women arrived at the hospital and how it could affect their health and the newborns. This is known as the "three delays" model, which relates mortality to a series of delays in obstetric care that prevent women from accessing skilled and effective care at various healthcare levels. These delays may be associated with personal, sociocultural, and institutional causes $[9,10]$.

Recent studies have replicated this methodology to understand maternal mortality and its effect on newborns. From this perspective, this study aimed to evaluate the association between delays in obstetric care and the presence of near-miss events and neonatal death.

\section{Methods}

This case-control study was designed to identify factors associated with near-miss neonatal morbidity conducted between January and December 2017 at the Assis Chateaubriand Teaching Maternity (Federal University of Ceará), a referral hospital for high-risk pregnancies in Northeast Brazil. Assis Chateaubriand Teaching Maternity provides healthcare services to predominantly low- income population. Approximately 5000 infants are delivered each year at the hospital. It offers Fetal Medicine services and has a Maternal and Neonatal Intensive Care Unit. Of the total 4929 deliveries, 392 newborns had at least one of the pre-established neonatal near-miss criteria in 2017. A total of 426 mothers, including cases and controls, agreed to respond to a specific interview about their experiences during pregnancy and delivery.

The study sample size included 142 cases initially selected using the neonatal near-miss criteria and 284 controls in a 1:2 ratio. If a patient would die, the case would be reclassified as death. The inclusion criteria was neonatal near-miss according to Silva et al. (2014) [7]: 5min Apgar score $<7$, weight $<1500$ g, gestational age $<$ 32 weeks, use of mechanical ventilation, or presence of congenital malformation. The control group included newborns who did not meet the eligibility criteria born immediately before or after a selected case.

The exclusion criteria for cases included the following: newborns whose information could not be obtained from medical records or by interview with family members; deliveries that were considered abortions $(<20$ gestational weeks and weight $<500 \mathrm{~g}$ ); newborns with malformations or chromosomal syndromes considered lethal; and deliveries that occurred outside the hospital environment (e.g., in an ambulance). For controls, the exclusion criteria included the following: newborns whose information could not be obtained from medical records or through interviews with family members and deliveries that occurred outside the hospital environment.

The newborns were followed-up during the neonatal period. After follow-up, cases and controls were reclassified by outcome: survival to neonatal period without near-miss criteria (true controls), near-miss, and neonatal death.

Cases and controls were identified through a survey of the birth records of the neonatology unit of the maternity ward. A standardized questionnaire was used to collect socioeconomic data, maternal characteristics, prenatal and newborn information, complications during pregnancy and childbirth, and the mother's previous health.

All mothers provided written informed consent form and were interviewed in the first $24 \mathrm{~h}$ after delivery.

The analysis of the three delays followed the criteria established by the World Health Organization [11]. The first delay was in deciding to seek appropriate medical help (family/patient) as follows. Refusal of care was identified when the mother did not seek prenatal care despite not desiring the pregnancy, did not attend appointments due to not liking the medical and nursing staff, the health unit being too far from home, or caring for another child, did not undergo tests due to lack of time, or hospital evasion; delay in seeking care was caused due to a change of address or other personal 
issues; and was unaware of the signs was when the mother did not know she was pregnant or sought care only when she was in a more severe clinical state.

The second delay was related to reaching an appropriate health service as follows. Absent or inadequate prenatal care occurred when the mother started prenatal care after the 12th gestational week, was unavailable to undergo all recommended tests, had fewer than six consultations, had no access to prenatal care due to a lack of staff or difficulties reaching high-risk prenatal carethe patient recognizes the need to start prenatal care, but cannot attend it because of difficulties beyond her control; difficult access due to a lack of beds, was when the pregnant woman went to more than one maternity ward seeking care in urgent/emergency situations; difficult access due to a lack of specialized care occurred when no hospital specialized in high-risk care or no specialized staff-data confirmed by transfer reports from the ambulance service; difficult communication between hospital and control center occurred when the patient arrived at the hospital with no guarantee of consultation or hospitalization; transportation problems were defined as the lack of an ambulancewhen the patient was referred from another health unit, but arrived by car or taxi; and difficult geographical access to health services was experienced when the patient could not reach the hospital for delivery.

The third delay regarded receiving good healthcare at the health unit included the following: delay in diagnosis, delay in transferring/referring the case, improper conduct with a patient, lack of medication or blood products, and delay in starting treatment. For example, delay in recognizing signs of severity in cases of pre-eclampsia and, therefore, need to initiate magnesium sulfate. The medical records were evaluated by two high-risk specialist obstetricians who were blinded to the group assignments. There was no disagreement regarding any of the evaluated cases. The assessment regarding the third delay was performed specifically to define it as a parameter in this study protocol. There is no audit service at the institution. All cases of maternal, fetal, and neonatal deaths are evaluated by the Death Committee, which included medical professionals, nurses, and epidemiologists. This committee seeks to determine whether death is avoidable, but does not directly determine the delays in healthcare.

The Pearson's chi-square and Fisher's exact tests were used in this study. Simple logistic regression was used to determine the strength of association of the three delay factors with near-miss and death outcomes for variables with $p$ values $<0.05$. Multinomial logistic regression included variables with $\mathrm{p}$ values $<0.05$ in simple regression [12]. Odds ratios (OR) were calculated with respective confidence intervals $(95 \% \mathrm{CI})$. Statistical tests did not consider values without information. SPSS version 24.0 for Windows ${ }^{\circ}$ and $\mathrm{R}$ version 3.31 software were used for the statistical analysis. The data were compiled using Excel $^{\circledR}$ software (2010). G* Power 3.1.9.2 software determined that the sample power was $98.3 \%$ [13]. The sample power was calculated a posteriori using the following input parameters: $\mathrm{z}$ tests - Logistic regression Options: Large sample z-Test, Demidenko (2007) with var. corr Analysis: Post hoc: Compute achieved power Input: Tail $(\mathrm{s})=$ Two Odds ratio $=2.27 \operatorname{Pr}(\mathrm{Y}=1 \mid \mathrm{X}=1) \quad \mathrm{H} 0=$ $0.382 \alpha$ err prob. $=0.05$ Total sample size $=426 R^{2}$ other $\mathrm{X}=0.038 \quad \mathrm{X}$ distribution $=$ Binomial $\mathrm{X}$ parm $\pi=0.46$ Output: Critical $\mathrm{z}=1.9599640$ Power $(1-\beta$ err prob $)=$ 0.9832087.

This study was approved by our institution's research ethics committee (no. 1,869,528) in compliance with Resolution 466/12 of the National Health Council on Research with Human Beings.

\section{Results}

Of the 4929 births, 392 newborns met at least one of the neonatal near-miss criteria. The sample included 142 cases and 284 controls selected using a specific interview with the three delay variables. The newborns were followed up during the neonatal period until hospital discharge or the 28th day of life (whichever occurred first). After follow-up, cases and controls were reclassified according to the outcomes: survival of the neonatal period without near-miss criteria (true controls), nearmiss, and neonatal death.

Of the variables studied, the mother's origin and occupation were associated with delays and neonatal nearmiss and death. Neonates of pardo mothers with higher education levels ( $\geq 8$ years), who were living with a partner in the capital, who do not work outside the home, who are aged 19-34 years, and with income less than the minimum were more prevalent (Table 1).

Of the mothers studied, $37.8 \%$ had a premature delivery and $62.9 \%$ had a cesarean section. Of the neonatal near-miss cases, $30.6 \%$ were classified as high-risk pregnancies and required specialized services. The mortality rate was $26.5 \%$. Regarding the number of consultations, $50.9 \%$ had less than six; of that group, $64.7 \%$ of the infants died (Table 2).

Among the three delay variables, absent or inadequate prenatal care and difficult access due to a lack of specialized services (second delay) and improper conduct with patient (third delay) showed statistical significance with $p<0.05$ (Table 3).

Multinomial logistic regression was used to determine the association between the three delay risk factors and neonatal near-miss and deaths. The variables with values of $p<0.05$ analyzed with multinomial logistic regression were absent or inadequate prenatal care, delayed access 
Table 1 Sociodemographic characteristics of the mothers by group and deaths. Fortaleza CE, 2017

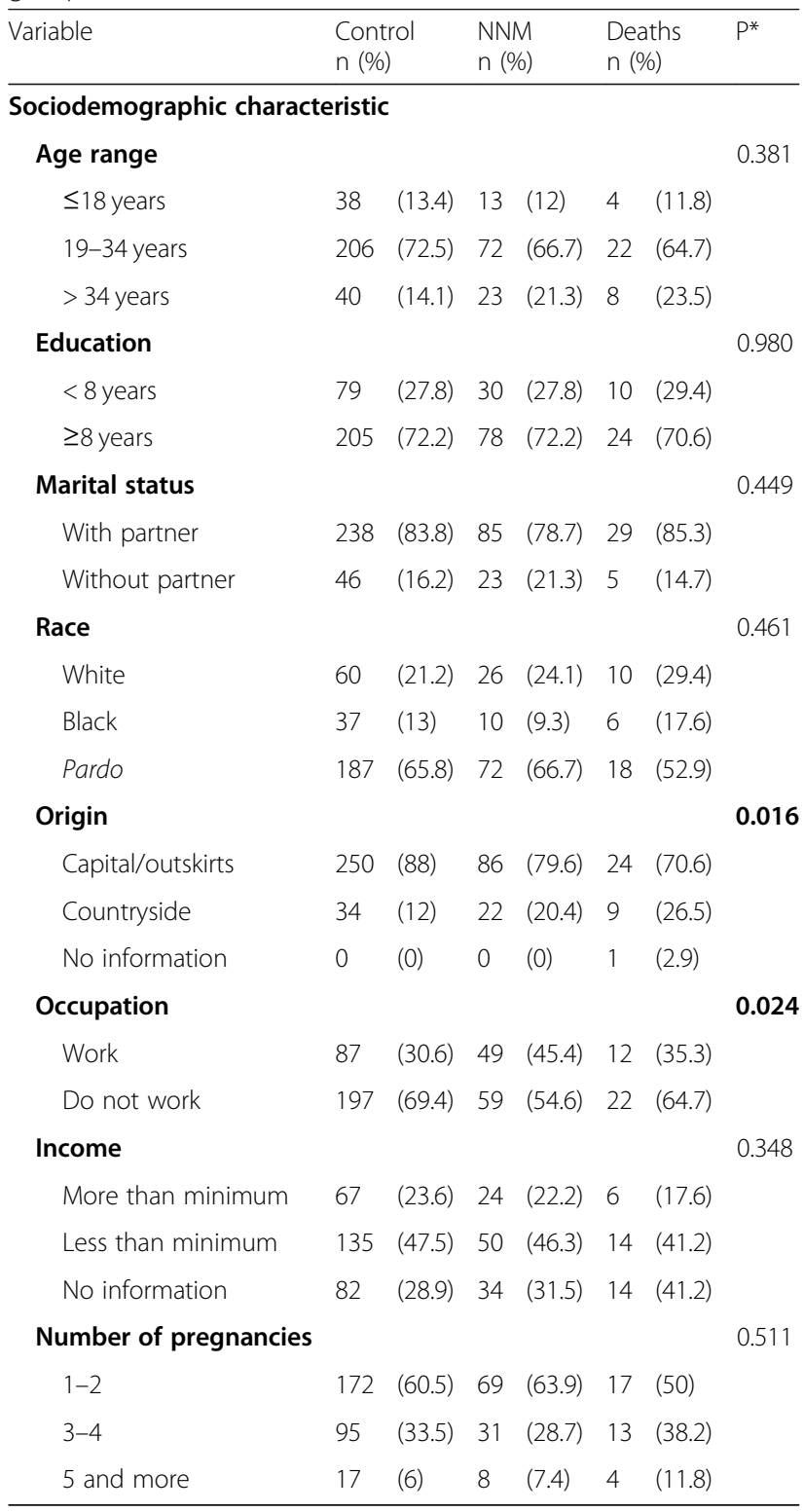

NNM Neonatal near-miss *Pearson's Chi-square test.

to health services due to a lack of specialized care, and improper conduct with the patient. Absent or inadequate prenatal care was significant in the intergroup comparisons between control and death and near-miss and death; delayed access to healthcare due to a lack of specialized services showed a significant intergroup association between control and death, and improper conduct with the patient also showed a significant intergroup association (Table 4).

Univariate and multinomial logistic regression analyses considering a combined outcome (near-miss and neonatal deaths) are shown in Tables 5 and 6 , respectively.

\section{Discussion}

The Brazilian Unified Health System (SUS) is public and universal, organized into three levels of care-primary (gateway, where most health problems should be solved), secondary (small hospitals and units with specialist doctors, equipped to provide laboratory imaging diagnostics), and tertiary (hospitals with the capacity to solve complex health problems, generally with surgical wards and intensive care units).

The primary care team is responsible for comprehensive care. The referral between one level and another should comply with agreements between cluster-located clinics forming the Health Care Networks (RAS). The healthcare system was designed in a way to reduce inequalities in access and coverage. Maternal-infant RAS is one of the system's priorities. However, there are often no available beds to attend specific cases at the tertiary medical facilities [14].

The changes in demographics, economy, and healthcare experienced by Brazil in the last three decades have caused profound changes in different spheres, especially in maternal and child healthcare. SUS enabled the implementation of many programs with a strong potential to reduce maternal and child mortality rates and managed to modify some health indicators in this context. Some public policies have also tried to reduce poverty through conditional cash transfers with the potential to contribute [1].

However, despite the advances, the rates of maternal and perinatal mortality are still high, mostly from causes, considered preventable. We are facing a great challenge as it cannot be guaranteed that the quality of services provided to the mother-child binomial is as planned and that the proposed programs are offered in the necessary quantity [15].

There is a need to identify local factors that persist favoring morbidity and mortality in this period of life, mainly because the Northeast is still one of the Brazilian regions with the highest rate of maternal and child morbidity and mortality.

The results showed that delays in obstetric care increase the risk of neonatal near-miss events and death. The most frequent delays were absent or inadequate prenatal care and delayed access to healthcare due to a lack of specialized service, both classified under the second delay, followed by improper conduct with the patient, classified under the third delay.

A study in eastern Uganda analyzing the three delay model to explain newborn morbimortality reported that the first and third delays contributed to two thirds of the neonatal death outcomes [16]' In another study, the outcome of neonatal mortality was attributed to the third delay [17].

Another study on the same subject that aimed to identify the association between delayed obstetric care and 
Table 2 Characteristics of prenatal care and pregnancy outcomes in controls, NNM cases, and deaths. Fortaleza CE, 2017

\begin{tabular}{|c|c|c|c|c|c|c|c|}
\hline Variable & $\begin{array}{l}\text { Control } \\
\text { n (\%) }\end{array}$ & & $\begin{array}{l}\text { NNM } \\
\text { n (\%) }\end{array}$ & & $\begin{array}{l}\text { Deaths } \\
\mathrm{n}(\%)\end{array}$ & & $P$ \\
\hline No. of prenatal consultations & & & & & & & $0.001 *$ \\
\hline$<6$ & 110 & $(38.7)$ & 55 & $(50.9)$ & 22 & $(64.7)$ & \\
\hline$\geq 6$ & 170 & $(59.9)$ & 50 & $(46.3)$ & 10 & (29.4) & \\
\hline No information & 4 & $(1.4)$ & 3 & $(2.8)$ & 2 & (5.9) & \\
\hline Prenatal service & & & & & & & $0.037^{*}$ \\
\hline Primary healthcare & 212 & $(74.6)$ & 70 & $(64.8)$ & 21 & (61.8) & \\
\hline Specialized care required (high-risk) & 60 & $(21.1)$ & 33 & (30.6) & 9 & (26.5) & \\
\hline Private clinic & 3 & $(1.1)$ & 2 & (1.9) & 1 & $(3.2)$ & \\
\hline No information & 9 & $(3.2)$ & 3 & (2.8) & 3 & (8.8) & \\
\hline Orientation on place of delivery & & & & & & & $0.912^{*}$ \\
\hline Yes & 186 & $(65.5)$ & 72 & $(66.7)$ & 21 & $(61.8)$ & \\
\hline No & 94 & (33.6) & 33 & (31.4) & 11 & (34.4) & \\
\hline No information & 4 & $(1.4)$ & 3 & (2.8) & 2 & (5.9) & \\
\hline Number of maternity hospitals visited & & & & & & & $0.170^{*}$ \\
\hline$\geq 3$ & 12 & $(4.2)$ & 2 & (1.8) & 1 & (2.9) & \\
\hline 2 & 82 & $(28.9)$ & 45 & $(41.7)$ & 12 & (35.3) & \\
\hline 1 & 187 & $(65.8)$ & 61 & $(56.5)$ & 21 & $(61.8)$ & \\
\hline No information & 3 & $(1.1)$ & 0 & $(0.0)$ & 0 & $(0.0)$ & \\
\hline If transferred & & & & & & & $<0.001 *$ \\
\hline Regulated & 21 & (7.4) & 18 & $(16.7)$ & 8 & (23.5) & \\
\hline Referred & 45 & (15.8) & 38 & (35.2) & 7 & (20.6) & \\
\hline Own discretion & 215 & (75.7) & 51 & $(47.2)$ & 19 & (55.9) & \\
\hline No information & 3 & $(1.1)$ & 1 & $(0.9)$ & 0 & $(0.0)$ & \\
\hline Type of delivery & & & & & & & $<0.001 * *$ \\
\hline Cesarean section & 160 & (56.3) & 86 & (79.6) & 22 & $(64.7)$ & \\
\hline Forceps & 2 & $(0.7)$ & 0 & (0) & 0 & (0) & \\
\hline Vaginal & 122 & (43) & 22 & (20.4) & 12 & (35.3) & \\
\hline
\end{tabular}

*Pearson's chi-square test; **Fisher's exact test

fetal death outcomes reported that the first, second, and third delays contributed to these outcomes [18], showing that delays in maternal care at any levels increase the chances of perinatal complications. We believe that neonatal morbimortality cannot be attributed to a single delay, but to a combination of factors that lead to an unfavorable outcome.

No cases of intrauterine death were evaluated. Cases and controls were selected at childbirth, and only live newborns were included. The first delay (in deciding to seek appropriate medical help, family/patient) was not associated with near-miss or neonatal death. This finding may be explained by the fact that $72.1 \%$ of the women were mothers with $\geq 8$ years of education, $82.6 \%$ were living with a partner, $84.5 \%$ were living in the capital, $70.4 \%$ were aged $19-34$ years, and $65.4 \%$ received an orientation at their place of delivery. This profile may have affected the result that $83.6 \%$ of the women did not delay seeking care, $96.5 \%$ were aware of the signs of pregnancy, and $87.1 \%$ did not refuse care. The prevalence of the first delay was low for all outcomes.

Low maternal education, lack of family support, marital status, maternal age, and lack of confidence about the health service are risk factors for poor maternal and neonatal outcomes $[15,19,20]$. These factors have traditionally been responsible for the worst neonatal outcomes. However, the factors were not significant in our analysis, probably because the population is very homogeneous; all with low socioeconomic status.

Our analysis showed that absent or inadequate prenatal care has a statistically significant association with both near-miss and/or death, with OR values of 1.9. The data showed that $47.2 \%$ of the pregnant women in this study started their prenatal care after 12 weeks of pregnancy, $44.8 \%$ had less than six consultations, $16.4 \%$ had difficulties in prenatal care, and $11.5 \%$ were not able to 
Table 3 The effect of the three delays by group and deaths. Fortaleza CE, 2017

\begin{tabular}{|c|c|c|c|c|c|c|c|}
\hline Delay type & Control & (\%) & NNM & (\%) & Death & (\%) & $\mathrm{P}$ \\
\hline \multicolumn{8}{|c|}{ 1. DELAY IN DECIDING TO SEEK APPROPRIATE MEDICAL HELP (FAMILY/PATIENT) } \\
\hline Delay seeking care & & & & & & & $0.153^{*}$ \\
\hline Yes & 50 & $(17.6)$ & 12 & $(11.1)$ & 8 & (23.5) & \\
\hline No & 234 & $(82.4)$ & 96 & $(88.9)$ & 26 & (76.5) & \\
\hline Unaware of pregnancy & & & & & & & $0.583^{* *}$ \\
\hline Yes & 10 & $(3.5)$ & 5 & (4.6) & 0 & (0) & \\
\hline No & 274 & $(96.5)$ & 103 & (95.4) & 34 & $(100)$ & \\
\hline Refusal of care & & & & & & & $0.317^{*}$ \\
\hline Yes & 33 & $(11.6)$ & 15 & $(13.9)$ & 7 & (20.6) & \\
\hline No & 251 & $(88.4)$ & 93 & $(86.1)$ & 27 & (79.4) & \\
\hline \multicolumn{8}{|c|}{ 2. DELAY IN REACHING APPROPRIATE HEALTH SERVICE } \\
\hline Absent/inadequate prenatal care & & & & & & & $0.001^{*}$ \\
\hline Yes & 90 & $(31.7)$ & 45 & $(41.7)$ & 21 & $(61.8)$ & \\
\hline No & 194 & $(68.3)$ & 63 & (58.3) & 13 & $(38.2)$ & \\
\hline Lacking specialized care & & & & & & & $<0.001 *$ \\
\hline Yes & 43 & $(15.1)$ & 39 & $(36.1)$ & 11 & (32.4) & \\
\hline No & 241 & $(84.9)$ & 69 & (63.9) & 23 & (67.6) & \\
\hline Lacking beds & & & & & & & $0.086^{*}$ \\
\hline Yes & 27 & $(9.5)$ & 4 & (3.7) & 1 & (2.9) & \\
\hline No & 257 & $(90.5)$ & 104 & (96.3) & 33 & $(97.1)$ & \\
\hline \multicolumn{8}{|c|}{ 3. DELAY IN RECEIVING CARE AT THE HEALTH UNIT } \\
\hline Delay in diagnosis & & & & & & & $0.502^{* *}$ \\
\hline Yes & 2 & $(0.7)$ & 2 & $(1.9)$ & 0 & (0) & \\
\hline No & 282 & $(99.3)$ & 106 & $(98.1)$ & 34 & $(100)$ & \\
\hline Delay in case transfer/referral & & & & & & & $0.198^{*}$ \\
\hline Yes & 8 & $(2.8)$ & 4 & (3.7) & 3 & (8.8) & \\
\hline No & 276 & $(97.2)$ & 104 & (96.3) & 31 & $(91.2)$ & \\
\hline Improper conduct with patient & & & & & & & $0.007^{*}$ \\
\hline Yes & 1 & $(0.4)$ & 5 & (4.6) & 1 & (2.9) & \\
\hline No & 283 & (99.6) & 103 & (95.4) & 33 & $(97.1)$ & \\
\hline Delay in initiating treatment & & & & & & & $0.256^{*}$ \\
\hline Yes & 5 & $(1.8)$ & 2 & (1.9) & 2 & (5.9) & \\
\hline No & 279 & $(98.2)$ & 106 & (98.1) & 32 & (94.1) & \\
\hline
\end{tabular}

*Pearson's chi-square test; **Fisher's exact test

Table 4 Logistic regression of the three delays by group and death outcomes. Fortaleza CE, 20172017

\begin{tabular}{|c|c|c|c|c|c|c|}
\hline \multirow[b]{2}{*}{ Variable } & \multicolumn{2}{|c|}{ Control $\times$ Near-miss } & \multicolumn{2}{|c|}{ Control × Death } & \multicolumn{2}{|c|}{ Near-miss $\times$ Death } \\
\hline & $\begin{array}{l}\text { OR }(95 \% \mathrm{Cl}) \\
\text { Gross }\end{array}$ & $\begin{array}{l}\text { OR }(95 \% \mathrm{Cl}) \\
\text { Adjusted }\end{array}$ & $\begin{array}{l}\text { OR }(95 \% \mathrm{Cl}) \\
\text { Gross }\end{array}$ & $\begin{array}{l}\text { OR }(95 \% \mathrm{Cl}) \\
\text { Adjusted }\end{array}$ & $\begin{array}{l}\text { OR }(95 \% \mathrm{Cl}) \\
\text { Gross }\end{array}$ & $\begin{array}{l}\text { OR }(95 \% \mathrm{Cl}) \\
\text { Adjusted }\end{array}$ \\
\hline $\begin{array}{l}\text { Absent or inadequate prenatal } \\
\text { care }\end{array}$ & $\begin{array}{l}1.5 \\
(0.9-2.4)\end{array}$ & $\begin{array}{l}1.5 \\
(0.9-2.4)\end{array}$ & $\begin{array}{l}1.5 \\
(0.9-2.4)\end{array}$ & $\begin{array}{l}3.4 \\
(1.6-7.1)\end{array}$ & $\begin{array}{l}3.5 \\
(1.7-7.3)\end{array}$ & $\begin{array}{l}2.3 \\
(1.03-5.0)\end{array}$ \\
\hline $\begin{array}{l}\text { Delay due to lack of specialized } \\
\text { service }\end{array}$ & $\begin{array}{l}3.2 \\
(1.9-5.3)\end{array}$ & $\begin{array}{l}3.1 \\
(1.8-5.1)\end{array}$ & $\begin{array}{l}2.7 \\
(1.2-5.9)\end{array}$ & $\begin{array}{l}2.5 \\
(1.1-5.7)\end{array}$ & $\begin{array}{l}0.8 \\
(0.4-1.9)\end{array}$ & $\begin{array}{l}0.8 \\
(0.4-1.9)\end{array}$ \\
\hline $\begin{array}{l}\text { Improper conduct with the } \\
\text { patient }\end{array}$ & $\begin{array}{l}13.9 \\
(1.6-120.9)\end{array}$ & $\begin{array}{l}12.1 \\
(1.4-108.8)\end{array}$ & $\begin{array}{l}8.7 \\
(0.5-142.5)\end{array}$ & $\begin{array}{l}7.7 \\
(0.5-132.8)\end{array}$ & $\begin{array}{l}0.6 \\
(0.1-5.5)\end{array}$ & $\begin{array}{l}0.7 \\
(0.1-5.1)\end{array}$ \\
\hline
\end{tabular}

OR Odds ratio; $\mathrm{Cl}$ Confidence interval. 
Table 5 Effect of the three delays considering combined outcome (near-miss and neonatal deaths). Fortaleza CE, 2017

\begin{tabular}{|c|c|c|c|c|c|}
\hline Delay type & Control & (\%) & NNM + Death & (\%) & $\mathrm{P}$ \\
\hline \multicolumn{6}{|c|}{ 1. DELAY IN DECIDING TO SEEK APPROPRIATE MEDICAL HELP (FAMILY/PATIENT) } \\
\hline Delay seeking care & & & & & $0.355^{*}$ \\
\hline Yes & 50 & $(17.6)$ & 20 & $(14.1)$ & \\
\hline No & 234 & $(82.4)$ & 122 & $(85.9)$ & \\
\hline Unaware of pregnancy & & & & & $>0.999 *$ \\
\hline Yes & 10 & $(3.5)$ & 5 & $(3.5)$ & \\
\hline No & 274 & $(96.5)$ & 137 & $(96.7)$ & \\
\hline Refusal of care & & & & & $0.216^{*}$ \\
\hline Yes & 33 & $(11.6)$ & 22 & $(12.9)$ & \\
\hline No & 251 & $(88.4)$ & 120 & $(87.1)$ & \\
\hline \multicolumn{6}{|c|}{ 2. DELAY IN REACHING APPROPRIATE HEALTH SERVICE } \\
\hline Absent/inadequate prenatal care & & & & & $0.003^{*}$ \\
\hline Yes & 90 & $(31.7)$ & 66 & $(46.5)$ & \\
\hline No & 194 & $(68.3)$ & 76 & $(53.5)$ & \\
\hline Lacking specialized care & & & & & $<0.001^{*}$ \\
\hline Yes & 43 & $(15.1)$ & 50 & $(35.2)$ & \\
\hline No & 241 & $(84.9)$ & 69 & $(64.8)$ & \\
\hline Lacking beds & & & & & $0.027^{*}$ \\
\hline Yes & 27 & $(9.5)$ & 5 & $(3.5)$ & \\
\hline No & 257 & $(90.5)$ & 137 & $(96.5)$ & \\
\hline \multicolumn{6}{|c|}{ 3. DELAY IN RECEIVING CARE AT THE HEALTH UNIT } \\
\hline Delay in diagnosis & & & & & $0.477^{* *}$ \\
\hline Yes & 2 & $(0.7)$ & 2 & (1.4) & \\
\hline No & 282 & $(99.3)$ & 140 & $(98.6)$ & \\
\hline Delay in case transfer/referral & & & & & $0.265^{*}$ \\
\hline Yes & 8 & $(2.8)$ & 7 & $(4.9)$ & \\
\hline No & 276 & $(97.2)$ & 135 & $(95.1)$ & \\
\hline Improper conduct with patient & & & & & $0.006^{* *}$ \\
\hline Yes & 1 & $(0.4)$ & 6 & $(4.2)$ & \\
\hline No & 283 & $(99.6)$ & 136 & $(95.8)$ & \\
\hline Delay in initiating treatment & & & & & $0.489^{* *}$ \\
\hline Yes & 5 & (1.8) & 4 & (1.9) & \\
\hline No & 279 & (98.2) & 106 & (98.1) & \\
\hline
\end{tabular}

*Pearson's chi-square test; **Fisher's exact test

Table 6 Logistic regression of the three delays by group, considering combined outcome (near-miss and neonatal deaths). Fortaleza CE, 2017

\begin{tabular}{lcc}
\hline Variable & \multicolumn{1}{c}{ Control } & $\begin{array}{c}\text { Near-miss + Death } \\
\text { OR (95\% Cl) Adjusted }\end{array}$ \\
\hline Absent or inadequate prenatal care & $(95 \%$ Cl) Gross & $\mathbf{1 . 9}(\mathbf{1 . 2 - 2 . 8 )}$ \\
Lacking beds & $\mathbf{1 . 9 ( 1 . 2 - 2 . 8 )}$ & $0.4(0.2-1.1)$ \\
Delay due to lack of specialized services & $\mathbf{0 . 4}(\mathbf{0 . 1}-\mathbf{0 . 9})$ & $\mathbf{2 . 8}(\mathbf{1 . 7 - 4 . 5 )}$ \\
Improper conduct with the patient & $\mathbf{3 . 5}(\mathbf{1 . 9 - 4 . 9 )}$ & $\mathbf{1 0 . 6}(\mathbf{1 . 2 - 9 1 . 8 )}$ \\
\hline
\end{tabular}

OR Odds ratio; $\mathrm{Cl}$ confidence interval. 
undergo all the recommended tests. These data may be due to some factors already described in the literature. For example, a Brazilian study that evaluated the government database on the National Program for Improving Access and Quality of Primary Care (PMAQ-AB) 2012/ 2013 showed that pregnant women are accessing and beginning prenatal consultations later than usual, mostly due to a lack of family planning. It is necessary to implement programs focused on educating and helping women identify pregnancy [21].

Despite having reached international indicators and almost equitable levels in all regions, the coverage of prenatal care in Brazil does not guarantee that efficient and high-quality consultations will be provided to these pregnant women; rather, they often show a lack of professional qualifications regarding comprehensive care for the pregnancy and delivery [21, 22]. All of these factors directly affect care conduct, delivery outcomes, and neonatal care, with a direct impact on negative neonatal outcome by increasing NNM and fetal deaths [23]. The quality of prenatal consultations was not assessed. The theoretical framework that we followed to define the first delay evaluates only objective data, such as gestational age at the beginning of care, number of consultations, and performance of laboratory tests recommended by scientific evidence. A prospective study that comes to evaluate the quality of these consultations and the understanding of the information by the patient and her family can bring even more concerning information.

The literature considers a delay in care for pregnant women a determining factor for negative outcomes when they require specialized care [24]. Mother's origin was statistically significant $(p=0.016)$ on the univariate evaluation. A total of 65 pregnant women came from the countryside; of them, 22 newborns suffered nearmiss events and nine died.

There are problems with the availability of hospital beds, a greater concentration of health services in large urban centers, lack of hospital expansion to keep up with population growth, structural and process deficiencies in the referral system, and a counter-referral flow that take these women from one institution to another, culminating in unfavorable maternal outcomes and effects on newborns [25].

Inequity remains the real problem in healthcare access as replicated in some studies [26]. We emphasize here that the region where this study was conducted still has a high rate of maternal and neonatal morbimortality.

Improper conduct with the patient was statistically significant to neonatal near-miss groups (adjusted OR, 12.1) but not neonatal death. When the combined death plus near-miss outcome was evaluated, the $O R$ value was 10.6. The study rates were extremely positive to the institution, reaching $98.4 \%$ of proper conduct with the patient after a specialized evaluation.

Our findings show that this is a very relevant issue as reported in a recent systematic review of the third delay, which showed that the third delay significantly contributed to maternal mortality and shed light on the importance of early recognition of maternal and fetal risks. Negative outcomes can occur even under assertive specialized care, but they will be minimized. A large proportion of negative outcomes are preventable [27]. There are multiple and complex reasons for delays involving a lack of supplies, lack of professional technical skills, and bad attitude toward the patient, among others $[28,29]$. It is worth mentioning that these data were collected at an undergraduate and graduate teaching maternity center that follows institutional protocols constantly reviewed based on scientific evidence. A good suggestion would be to offer training to all professionals providing maternity and neonatal care on institutional protocols and available scientific evidence, complemented with periodic evaluations of the results after implementing changes.

A study limitation was the possibility of selection bias as the sample was collected from a reference maternity hospital providing high-complexity maternal and neonatal care for the entire state, which enabled the identification of more cases of neonatal near-miss compared to other maternity hospitals, thereby limiting the generalization of our results to medium- and lowcomplexity maternity hospitals. However, it can be assumed that the results can be extrapolated to several other maternity hospitals in Brazil and other countries that share the same clinical and socioeconomic scenario.

This study is important since it paves the way for new studies in terms of scenarios and other designs. This was the first study developed in the state to evaluate severe neonatal morbidity associated with the three delays, which included maternal reports on difficulties obtaining healthcare, as well as data from medical records throughout pregnancy, delivery, childbirth, and neonatal care. Diversified approach including strategies for improving prenatal care, expanding state hospital structures to reduce transfers to better hospitals, and increasing qualified technical and human resources in emergency care is vital. Collaboration among departments and healthcare service providers is necessary to manage maternal and neonatal care.

\section{Conclusions}

A clear association was found among the occurrence of delays in accessing obstetric care and near-miss events and neonatal death. The most frequent delays were absent or inadequate prenatal care, delay accessing healthcare due to a lack of specialized service, and improper conduct with the patient. 


\section{Abbreviations}

PMAQ-AB: National program for improving access and quality of primary care; OR: Odds ratio; IC: Confidence interval; NNM: Neonatal near-miss

\section{Acknowledgements}

Authors thank Maternidade Escola Assis Chateaubriand / MEAC/ UFC, study participants, data collectors and supervisors.

\section{Authors' contributions}

OMCC, AJML, and FHCC conceived and designed the study. OMCC and FNBL supervised the data collection. ABVJ, AJML, and FHCC performed the data analysis. OMCC, RAN, OAACB, ECMdeC, and FHCC involved in the interpretation of data. OMCC, MCCA and FNBL drafted the manuscript. OMCC, MCCA RAN, OAACB, ECMdeC, and FNBL critically edited the manuscript. OMCC, MCCA, and FNBL finalized the manuscript. All authors read and approved the final manuscript.

\section{Funding}

No funding was received.

\section{Availability of data and materials}

The datasets used and/or analyzed during the current study are available from the corresponding author upon reasonable request. All co-authors gave full responsibility to the corresponding author to share and/or discuss with editors and reviewers.

\section{Ethics approval and consent to participate}

This study was approved by the Research Ethics Review Committee (RERC) of Maternidade Escola Assis Chateaubriand / MEAC/ UFC dated December 15, 2016, and numbered 1.869.528 CAAE: 62597616.9.0000. Written informed consent was taken from all of the study participants. Confidentiality of responses was maintained throughout the study.

\section{Consent for publication}

Not applicable.

\section{Competing interests}

The authors declare that they have no competing interests.

\section{Author details}

'Departamento de Saúde Comunitária / Universidade Federal do Ceará Fortaleza, Fortaleza, CE, Brazil. ²Departamento de Saúde Materno Infantil / Universidade, Fortaleza, CE, Brazil. ${ }^{3}$ Universidade de Fortaleza/ UNIFOR, Fortaleza, CE, Brazil. ${ }^{4}$ Departamento de Saúde da Mulher, da Criança e do Adolescente UFC, Fortaleza, Brazil. ${ }^{5}$ Maternidade Escola Assis Chateaubriand, Fortaleza, CE, Brazil.

Received: 15 January 2020 Accepted: 23 July 2020

Published online: 29 July 2020

\section{References}

1. França E, Lansky S. Mortalidade infantil neonatal no Brasil: Situação, tendências e perspectivas [Internet]. [publisher unknown]: ABEP; 2008 [cited 2019 Feb 22]. Available from: http://www.abep.org.br/publicacoes/index. php/anais/article/view/1763/1723.

2. Barros FC, Matijasevich A, Requejo JH, Giugliani E, Maranhao AG, Monteiro CA, et al. Recent trends in maternal, newborn, and child health in Brazil: progress toward millennium development goals 4 and 5. Am J Public Health. 2010;100(10):1877-89. https://doi.org/10.2105/AJPH.2010.196816.

3. Pileggi C, Souza JP, Cecatti JG, Faúndes A. Neonatal near miss approach in the 2005 WHO global survey Brazil. J Pediatr. 2010;86:21-6.

4. World Health Organization; United Nations Children's Fund; World Bank Group; United Nations. Levels and trends in child mortality report 2017: estimates developed by the UN Inter-agency Group for Child Mortality Estimation [Internet]. New York: United Nations Children's Fund; 2017 [cited 2019 Mar 22]. Available from: https://www.unicef.org/media/48871/file/ Child_Mortality_Report_2017.pdf.

5. Almeida FM, Alencar GP, Shoeps D, Novaes HMD, Campbell O, Rodrigues LC. Sobrevida e fatores de Risco Para mortalidade neonatal em um coyote de nascidos vivos de muito baixo peso ao nascer, na Regiao Sul do municipio de Sao Paulo, Brasil. Cad De Saude Publica. 2011;27:1088-98.
6. Assis HM, Siviero PCL, Drumond LF, Machado CJ. Óbitos fetais sob o prisma da evitabilidade: análise preliminar de um estudo Para o município de Belo Horizonte. Cad Saúde Colet. 2014;22:314-7.

7. Silva AAMD, Leite AJM, Lamy ZC, Moreira MEL, Gurgel RQ, Cunha AJLA, et al. Morbidade neonatal near miss na pesquisa Nascer no Brasil. Cad Saúde Publica. 2014;30:S182-91.

8. Saleem S, McClure EM, Goudar SS, Patel A, Esamai F, Garces A, et al. A prospective study of maternal, fetal and neonatal deaths in low- and middle-income countries. Bull World Health Organ. 2014;92:605-12.

9. Thaddeus S, Maine D. Too far to walk: maternal mortality in context. Soc Sci Med. 1994;38:1091-110.

10. Pacagnella RC, Cecatti JG, Parpinelli MA, Sousa MH, Haddad SM, Costa ML, et al. Delays in receiving obstetric care and poor maternal outcomes: results from a national multicentre cross-sectional study. BMC Pregnancy Childbirth. 2014:14:159.

11. World Health Organization. Making every baby count: audit and review of stillbirths and neonatal deaths [Internet]. Geneva: WHO; 2016. p. 136. [cited 2018 Dez 22] Available from: https://apps.who.int/iris/bitstream/handle/ 10665/249523/978924151 1223-eng.pdf;jsessionid= AA95F8E9D4C760EAB35C582460A84C51? sequence $=1$.

12. Field A, Miles J, Field Z. Discovering statistics using R [internet]. London: SAGE publications Ltd; 2012. [cited 2019 Feb 22]. Available from: https://nyu cdsc.github.io/learningr/assets/discoveringstatistics.pdf.

13. Faul F, Erdfelder E, Lang AG, Buchner A. G*power 3: a flexible statistical power analysis program for the social, behavioral, and biomedical sciences. Behav Res Methods. 2007;39(2):175-91. https://doi.org/10.3758/BF03193146.

14. Leal MC, Szwarcwald CL, Almeida PVB, Aquino EML, Barreto ML, Barros F, et al. Saúde reprodutiva, materna, neonatal e infantil nos 30 anos do Sistema Único de Saúde (SUS). Ciênc Saúde coletiva 2018;23(6)1915-1928. https://doi.org/https://doi.org/10.1590/1413-81232018236.03942018.

15. Lansky S, Friche AAL, Silva AAM, Campos D, Bittencourt SDA, Carvalho ML, et al. Birth in Brazil survey: neonatal mortality, pregnancy and childbirth quality of care. Cad Saúde Pública. 2014;30:S192-207.

16. Waiswa P, Kallander K, Peterson S, Tompson G, Pariyo W. Using the three delays model to understand why newborn babies die in eastern Uganda. Tropical Med Int Health. 2010;15:964-72.

17. Mbaruku G, van Roosmalen J, Kimondo I, Bilango F, Bergstrom S. Perinatal audit using the 3-delays model in western Tanzania. Int J Gynaecol Obstet. 2009;106:85-8.

18. Martins MCF, FEdL F, Viana Júnior AB, Correia LL, FLP I, RdC $P$, et al. Pregnancies with an outcome of fetal death present higher risk of delays in obstetric care: a case-control study. PLoS One. 2019;14:e0216037.

19. Borba GG, Neves ET, Arrué AM, Silveira A, Zamberlan KC. Fatores associados à morbimortalidade neonatal: um estudo de revisão. Saúde (Santa Maria). 2014;40:9-16

20. Niyitegeka J, Nshimirimana G, Silverstein A, Odhiambo J, Lin Y, Nkurunziza T, et al. Longer travel time to district hospital worsen neonatal results: a retrospective cross-sectional study of the effect of delay in receiving emergency cesarean section in Rwanda. BMC Pregnancy Childbirth. 2017;17:242

21. Mallmann MB, Boing AF, Tomasi YT, Anjos JC, Boing AC. Evolution of socioeconomic inequalities in conducting prenatal consultations among Brazilian parturient women: analysis of the period 2000-2015. Epidemiol Serv Saude. 2018;27(4):e2018022. https://doi.org/10.5123/s167949742018000400014

22. Domingues RMSM, Leal MC, Hartz ZMA, Dias MAB, Vettore MV. Acesso e utilização de serviços de pré-natal na rede SUS do município do Rio de Janeiro, Brasil. Rev Bras Epidemiol. 2013;16:953-65.

23. Shroff BD, Ninama NH. A call for eminence obstetrics care by way of "neonatal near miss" events (NNM): a hospital-based case-control study. J Obstet Gynecol India. 2019;69(1):50-5.

24. Nascimento RM, Leite AJM, Almeida NMGS, Almeida PC, Silva C. Determinants of neonatal mortality: a case-control study in Fortaleza, Ceará state, Brazil. Cad Saúde Pública. 2012;28:559-72.

25. Menezes DC, Leite IC, Schramm JM, Leal MC. Avaliação da peregrinação anteparto numa amostra de puérperas no Município do Rio de Janeiro, Brasil, 1999/2001. Cad Saúde Pública. 2006;22:553-9.

26. Matthews Z, Channon A, Neal S, Osrin D, Madise N, Stones W. Examining the "urban advantage" in maternal health care in developing countries. PLoS Med. 2010;7(9):pii-e1000327.

27. Knight HE, Self A, Kennedy SH. Why are women dying when they reach hospital on time? A systematic review of the 'third delay'. PLoS One. 2013;8: e63846. 
28. Okong P, Byamugisha J, Mirembe F, Byaruhanga R, Bergstrom S. Audit of severe maternal morbidity in Uganda-implications for quality of obstetric care. Acta Obstet Gynecol Scand. 2006;85:797-804.

29. Essendi H, Mills S, Fotso JC. Barriers to formal emergency obstetric care services utilization. J Urban Health. 2011;88:5356-69.

\section{Publisher's Note}

Springer Nature remains neutral with regard to jurisdictional claims in published maps and institutional affiliations.

Ready to submit your research? Choose BMC and benefit from:

- fast, convenient online submission

- thorough peer review by experienced researchers in your field

- rapid publication on acceptance

- support for research data, including large and complex data types

- gold Open Access which fosters wider collaboration and increased citations

- maximum visibility for your research: over $100 \mathrm{M}$ website views per year

At BMC, research is always in progress.

Learn more biomedcentral.com/submissions 